\title{
A Demographic Analysis of Social Sustainability Performance in South Africa
}

\author{
Sandra Perks and Elroy E. Smith
}

\begin{abstract}
Strong moral leadership impacts the ethical behaviour and social performance of organizations. By accepting and practising corporate social responsibility and sustainability principles, organizations are more responsive towards the concerns and needs of their employees and other stakeholders. This paper sets out to gauge the perceptions of managers in the Nelson Mandela Metropole, South Arica regarding social sustainability performance. A self-administered questionnaire was distributed to a non-probability convenient sample of 105 managers to investigate whether there are relationships between the independent variables (social responsibility and sustainability) and dependent variables (classification data). The results revealed only highly significant relationships between sustainability and some demographic characteristics. Practical guidelines are provided how management can incorporate corporate social responsibility and sustainability issues in daily activities of organizations to enhance their social sustainability performance.
\end{abstract}

Index Terms-Management, social responsibility, sustainability, social sustainability performance.

\section{INTRODUCTION}

Managers have many responsibilities which engage them in a wide range of activities [1]. A manager's job can be thought of as a series of attempts to address the concerns of stakeholders. The organization's survival and continuing success depend upon the ability of its managers to create sufficient wealth, value or satisfaction for each stakeholder group [2]. Stakeholders expect organizations to address social sustainability. Corporate social responsibility (CSR) can be viewed as distinguishing right from wrong and being a good corporate citizen [3]. Sustainability refers to economic development that generates wealth and meets the needs of the current generation while saving the environment so that future generations' needs are met as well [4]. Social sustainability is the process to change the lives of people in communities [5].

In South Africa, the CSR concept became popular in 1994 with the publication of the King I report which outlined an inclusive stakeholder approach to governance [6]. This report was revised in 2002 (King II report) and also assigned responsibility for the governance of ethics to the board of directors [7]. This report was further extended in the King III report which recommends that organizations report on the triple bottom-line and not on financial performance only and review the three components of sustainability, namely

Manuscript received April 6, 2014, revised May 18, 2014.

Sandra Perks is with the Nelson Mandela Metropolitan University (e-mail: Sandra.perks@nmmu.ac.za). economic, social and environmental [8].

With heightened public interest in social responsibility, many organizations are discovering that they cannot avoid having people evaluate how well they perform. If an organization takes into consideration societal concerns while still progressing economically, it is known as sustainable development [1]. Corporate sustainability focuses on rethinking business beyond corporate social responsibility activities which requires systemic corporate cultural changes [9]. Strong moral leadership was found to have a major impact on ethical behavior of employees and managers [10]. With a philosophy of sustainability, managers weave social concerns into every strategic decision, revise policies and procedures to support sustainability efforts, and measure their progress toward sustainability goals [4].

Several studies have examined how consumers and investors evaluate organizations with regard to being ethical and socially responsible [10]. Limited research has specifically looked at the perceptions of managers on social sustainability, specifically based on demographical characteristics. For this reason, this paper explores the perceptions of managers on social sustainability (social responsibility and sustainability) and indicates how demographic characteristics can play a role in shaping managerial perceptions regarding social sustainability.

\section{Management OF Social Sustainability}

Management refers to the running of an organization and can include top-, middle-, line-and staff management. Management has for a long time been faced with the social task of managing people and organizing activities, but it does not mean they are regarded as socially sound or equitable [11]. The demands on managers from various stakeholder groups and response to the competitive environment stimulate the need for corporate social responsibility [12]. The responsibilities of managers are to manage the organization's mission, culture and objectives and employee well-being [13].

It was found that managers view CSR as a moral duty towards the society and not as a strategic tool [14]. There is a moderate to strong relationship between perceived integrity and the demonstration of transformation leadership behaviors [10].CSR disclosure and reporting is regarded as corporate image management as it focuses on creating positive customer perceptions or a good image of the organization by supporting a good cause. This reasoning could be driven by the manager's personal values in terms of self-interest or moral reasoning [12]. Managers and supervisors were found to have less favorable views on their employers' support for CSR [15]. 
Lack of a proper attitude of management is a limited factor of poor CSR performance and sustainability [16]. The values of sustainability have to permeate throughout the organization starting with the chief executive through to senior-, middle-, and junior management to staff [17]. Furthermore, it was found that a reason why organizations cannot be socially responsible is that managers do not engage in employee welfare activities in terms of a workplace safety program, violate human rights and engage in illegal activities [16].

The importance of board and senior management commitment towards sustainability cannot be stressed enough. Managers must understand and analyze the key sustainability drivers for the organizations and integrate them into the organization's strategy and set sustainability targets and objectives and measure progress made [1]. Coaching interventions are required to close the gap in the perception of managers and stakeholders regarding social performance and sustainability [18].

Training may prompt managers to give social sustainability a higher priority in their daily decision-making. There is little evidence that demographic factors affect social sustainability [19]. Empirical results regarding demographic differences are often ambiguous [20]. This ambiguity in organizational demography is due to the fact that demographic diversity in an organization often leads to a wide divergence of opinions [21].

\section{RESEARCH METHODOLOGY}

To investigate managerial perceptions regarding social sustainability, a quantitative research approach was followed. A final non-probability convenience sample of 105 managers was obtained. The Nelson Mandela Metropole was chosen as it was convenient, saved time and was more cost effective to administer the sample. It must be noted that the sample was restricted to the Nelson Mandela Metropole only and did not include any other regions in South Africa. However, the researchers ensure that managers of 105 different organizations in different industries and with different employment sizes were surveyed. It was rather difficult to get managers to avail themselves to participate in the survey. The self-administered comprised two sections:

1) Section A deals with perceptions of social responsibility

(five variables) and sustainability performance of organizations (six variables). A total of 11 variables/statements are used. The type of ordinal scale used is a five-point Likert-type scale, ranging from strongly agree to strongly disagree.

2) Section B provides classification data (demographic characteristics) of respondents and contains a nominal scale of measurement, using six categorical variables.

Several specific organizational characteristics serve as data classification (independent variables) in this study. These include type of industry; employment sector and size; income and extent of reporting corporate social performance. A total of 10 null-hypotheses were formulated. There were two factors and five classification data variables. However, only those independent variables that show significant relationships with the dependent variables (social responsibility and sustainability) are reported. No relationships were found between demographic data and social responsibility. The hypotheses with significant relationships are:

$\mathrm{HO}_{1}$ : There is no relationship between managerial perceptions of sustainability and size of an organization.

$\mathrm{HO}_{2}$ : There is no relationship between managerial perceptions of sustainability and income of an organization.

$\mathrm{HO}_{3}$ : There is no relationship between managerial perceptions of sustainability and extent of the organization's corporate social responsibility reporting.

In order to pre-test the questionnaire, it was given to a few managers of organizations and academics in the field of management, ethics and statistics. After processing and analyzing the data from this pilot study, the questionnaire was refined and some minor changes were made regarding wording, sequence and layout. The returned questionnaires were inspected to determine their acceptability, edited where necessary, and coded. The statistical computer package SPSS-PC was used to process the results. Data was analyzed using descriptive statistics (e.g. mean and standard deviation), frequency distributions, factor analysis and analysis of variance.

\section{EMPIRICAL RESULTS}

Table I provides a demographical profile of the respondents of this study.

TABLE I: DEMOGRAPHICAL PROFILE OF RESPONDENTS

\begin{tabular}{|c|c|c|}
\hline Characteristic & Category & $\%$ \\
\hline \multirow{10}{*}{ Type of industry } & Manufacturing & 36 \\
\hline & Banking and retail & 23 \\
\hline & & \\
\hline & & \\
\hline & Communication & 5 \\
\hline & Travel, tourism and transport & 7 \\
\hline & Construction & 4 \\
\hline & Agriculture and fishing & 7 \\
\hline & Other & \\
\hline & No response & \\
\hline \multirow{3}{*}{ Employment sector } & Private & 69 \\
\hline & Public & 30 \\
\hline & No response & \\
\hline \multirow{3}{*}{ Employment size } & Small $(<199)$ & 52 \\
\hline & Medium (200-499) & $\begin{array}{l}13 \\
35\end{array}$ \\
\hline & Large $(500+)$ & \\
\hline \multirow{5}{*}{ Turnover } & 0 - R999 999 & 22 \\
\hline & R1 - R4,999 999 million & 21 \\
\hline & R5 - R9,999 999 million & 40 \\
\hline & Above R10 million & 7 \\
\hline & No response & \\
\hline \multirow{3}{*}{$\begin{array}{l}\text { Social performance } \\
\text { reporting }\end{array}$} & Yes & 70 \\
\hline & No & 29 \\
\hline & No response & \\
\hline
\end{tabular}

From the results in Table I, it is clear that most of the respondents are economically active in the manufacturing industry (36\%) and $23 \%$ are employed in the banking and retail sector respectively. Most of the respondents are 
employed in the private sector $(69 \%)$ with $52 \%$ employed in small organizations and $35 \%$ in large organizations. It appears $22 \%$ of the organizations surveyed have a turnover of less than one million rand, while $40 \%$ have a turnover in excess of ten million rand. It was interesting to notice that $70 \%$ of the respondents indicated their organizations engage in social performance reporting.

Table II provides an overview of the most important and significant descriptive statistics on perceptions regarding social responsibility and sustainability.

TABLE II: DESCRIPTIVE STATISTICS

\begin{tabular}{lllll}
\hline Items & Factors & Mean & $\begin{array}{l}\text { Standard } \\
\text { deviation }\end{array}$ & $\begin{array}{l}\text { Cronbach's } \\
\text { alpha }\end{array}$ \\
\hline A1-5 & $\begin{array}{l}\text { Social } \\
\text { responsibility }\end{array}$ & 3.93 & 0.56 & 0.71 \\
\hline A6-11 & Sustainability & 3.80 & 0.67 & 0.76 \\
\hline
\end{tabular}

In analyzing the measure of central tendency (mean values) for the factors used in Section A of the questionnaire, it appears that most values cluster around point four of the scale (agree). Measures of dispersion, by means of low standard deviation scores indicate that respondents tended not to vary much in their responses regarding the two factors. The reliability coefficients of Cronbach's alpha for the two factors are all above 0.7 , so can be regarded internally reliability.

The purpose of the ANOVA analysis is to investigate the relationship between the independent and dependent variables and to test the stated hypotheses. Only those ANOVA results that show significant relationships between the independent and dependent variables are reported and those that exhibit no significant relationships are excluded from this discussion. Table III presents the ANOVA results.

\begin{tabular}{lccc}
\multicolumn{4}{c}{ TABLE III: ANOVA RESULTS } \\
\hline $\begin{array}{l}\text { Dependent variable: } \\
\text { Sustainability performance }\end{array}$ & F-Test & P-Value & $\mathrm{H} 0$ \\
$\begin{array}{l}\text { Independent variable } \\
\text { Size of organization }\end{array}$ & 8.898 & 0.000 & $\mathrm{H}_{1 \mathrm{a}}$ \\
\hline Income of organization & 6.503 & 0.000 & $\mathrm{H}_{2 \mathrm{a}}$ \\
\hline $\begin{array}{l}\text { Extent of reporting social } \\
\text { performance }\end{array}$ & 10.217 & 0.002 & $\mathrm{H}_{3 \mathrm{a}}$ \\
\hline
\end{tabular}

The null-hypotheses $\left(\mathrm{HO}_{1}\right.$ to $\left.\mathrm{HO}_{3}\right)$ can, in all cases, be rejected and the alternative hypotheses can be accepted. These null-hypotheses fall within the rejection region ( $p<$ 0.05 and large F-statistic values), which indicate that there is a significant relationship (difference) between the managerial perceptions of sustainability performance and certain classification data variables (alternative hypotheses accepted which indicate that there are significant relationships between the tested variables).

There are significant relationships or differences between sustainability performance and the independent variables: size, income and extent of social responsibility reporting. No relationships exist between the perceptions of social responsibility and all the classification data variables. As significant differences between mean values were found, further post-hoc tests (such as the Scheffé's test) were conducted as to identify where the differences occur, but are not reported here, as it falls beyond the scope of this paper.

\section{CONCLUSIONS AND RECOMMENDATIONS}

In literature, it was indicated that management can play a major role in the implementation of social responsibility and sustainability initiatives. The personal values and self-interests of managers in terms of social sustainability performance impact how they address it. Furthermore, a leadership style such as transformational leadership can be linked to a manager's perceived integrity. However, managers have a problem in the implementation of social sustainability performance initiatives due to lack of employee commitment. Literature also indicates that due to demographic diversity there is ambiguity with regards to the perceptions of the extent of social sustainability performance needed in an organization. By accepting, practising and performing in terms of social responsibility and sustainability, organizations would be more responsive towards the social sustainability concerns of stakeholders.

From the empirical results, there appears to be highly significant relationships between managerial perceptions of sustainability performance and size, income and extent of social organizational responsibility reporting ( $\mathrm{H} 01$ a to $\mathrm{H} 03 \mathrm{a}$ rejected). No relationships exist between perceptions regarding social responsibility performance and the classification data variables. Organizations with different employment sizes and income levels have different perceptions regarding sustainability performance. Organizations, which do report on social responsibility performance, will have different perceptions of sustainability performance than those not reporting.

It is recommended that even small organizations with lower income levels, which often struggle to make profit and survive, should strive towards long-term sustainability performance. The focus should not only be on reporting financial performance, but also on their social responsibility performance. To ensure that management and employees alike share the same views on social responsibility and sustainability performance, organizations should:

1) Appoint managers with ethical morals and integrity.

2) Regard CSR and sustainability as a strategic tool, not as a moral duty only.

3) Align the mission, culture, objectives and social sustainability strategies.

4) Engage in employee welfare activities (workplace safety programmes, respecting human rights).

5) Consider and accept broader social responsibility and sustainability performance than required by law.

6) Create a positive employee attitude towards social sustainability activities.

7) Cascade sustainable social performance values from chief executive to employees.

8) Appoint a competent committed board striving towards social sustainability performance.

9) Understand and analyze key social sustainability drivers and integrate them into their strategies.

10) Set social sustainability performance targets and include it in employees' performance appraisal. 
11) Advocate ethical norms even if detrimental to short-term profits.

\section{REFERENCES}

[1] D. Hellriegel, S. E. Jackson, J. Slocum, and G. Staude, Associates Management, 2 nd ed., Cape Town: Oxford Publishers, 2006.

[2] M. B. E. Clarkson, "A stakeholder framework for analyzing and evaluating corporate social performance," Academy of Management Review, vol. 20, no. 1, pp. 92-117, 1995.

[3] D. Theron, "Corporate social responsibility: A pharmaceutical industry analysis," Acta Commercii, vol. 5, pp.1-12, 2005.

[4] R. Daft, The New Era of Management, 2 nd ed., United States: Thomson South-Western, 2008

[5] S. McKenzie. (2004). Social sustainability: Towards some definitions, Hawke Research Institute Working Paper Series. University of South Australia, Magil, South Australia. [Online]. Available: https://atn.edu.au/Documents/EASS/HRI/working-papers/wp27.pdf

[6] J. J. Asangu, "The history of corporate social responsibility," Journal of Business and Public Policy., vol. 1, no. 2, pp. 1-18.

[7] G. J. Rossouw. "Business ethics and corporate governance in the Second King Report: Farsighted or futile?" Koers, vol. 67, no. 4, pp. 405-419, 2002

[8] A. B. Carroll and A. K. Buchholtz, Organization and Society: Ethics and Stakeholder Management, Ohio: Thomson South-Western, 6 th ed. 2006.

[9] S. S. Gao and J. J. Zhang, "Stakeholder engagement, social auditing and corporate sustainability," Business Process Management Journal, vol. 12, no. 6, pp. 722-740, 2006.

[10] R. Cacioppe, N. Forster, and M. Fox, "A survey of managers' perceptions of corporate ethics and social responsibility and actions that may affect companies' success," Journal of Business Ethics, vol. 82, pp. 681-700, 2007.

[11] S. Schaltegger, C. Herzig, O. Kleiber, and J. Müller, Sustainability Management in Business Enterprises: Concepts and Instruments for Sustainable Organization Development, Centre for Sustainaiblity Management (CSM), University of Lueneburg, 2002.

[12] C. A. Hemingway and P. W. Maclagan, "Managers' personal values as drivers of corporate social responsibility," Journal of Business Ethics, vol. 30, pp. 33-44, 2004.

[13] J. E. Tang, "Ethical corporate social responsibility: A framework for managers," Journal of Ethics, vol. 14, pp. 125-132, 1995.

[14] B. R. Chapagain, "Management views on corporate social responsibility in commercial banks of Nepal," Socio Economic Development Panorama, vol. 1, no. 3, pp. 119-130, 2008.

[15] Kennexa Research Institute. (2010). Employees recognize and value corporate social responsibility initiatives. [Online]. Available: http://www.kenexa.com/getattachment/7f1a2e8d

[16] M. A. Mamun and Z. U. Ahmed, "Manager's vision for corporate social responsibility," European Journal of Scientific Research., vol. 30, no. 4, pp. 631-648, 2009.

[17] T. Paramasivan. (2010). Sustainable reporting. [Online]. Available: http://www.experiencefestival.com/wp/article/sustainability-reporting

[18] M. Zollo. (2008). Corporate social responsibility: Are companies responding to social demands? [Online]. Available: http://www.knowledge.insead. edu/csrresponse080104.cfm

[19] G. Williams. (2005). Some determinants of the socially responsible investment decision: A cross country study. [Online]. Available: http://ssrn.com/abstract=905189
[20] M. A. Carpenter, "The implications of strategy and social context for the relationship between top management heterogeneity and firm performance," Strategic Management Journal, vol. 23, no. 3, pp. 275-284, 2002.

[21] R. Reagans, E. Zukerman, and B. Mcevily, "How to make the team: Social networks vs. demographic as criteria for designing effective teams," Administrative Science Quarterly, vol. 49, no. 1, pp. 101-133, 2004.

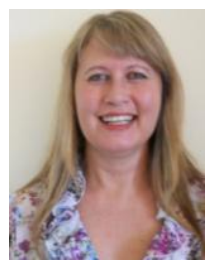

Elroy E. Smith was born in Joubertina, South Africa on 9 March 1961. She graduated from B Comm (business management) University of Port Elizabeth, South Africa in 1981, she got a HED (post graduate) University of South Africa, Pretoria, South Africa in 1986, and MBA Buckinghamshire Chilterns Business School, University of Brunel, London, Britain in 1998, and PhD degree (small business management) Vista University, Port Elizabeth, South Africa in 2002.

She has 4 years banking experience and 28 years lecturing experience. She has published 19 articles in national and international journals and presented papers at 41 conferences, mostly at international conferences. She contributed towards 9 chapters in 5 academic textbooks on small business and strategic management. She is currently a full professor at the Nelson Mandela Metropolitan University in Port Elizabeth, South Africa. Her main research interests are SMMEs, strategic management, marketing, ethics and social responsibility and environmental sustainability.

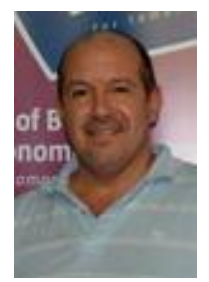

Sandra Perks is a member of the Southern African Institute of Management Sciences, a reviewer for many national and international journals and conferences, the Nelson Mandela Metropolitan University institutional research driver for sustainable local economic development, Business Women Virtual board member and Enactus board member.

Prof. Smith was born in Port Elizabeth, South Africa on 19 June 1965. He graduated from B Comm (business management) University of Port Elizabeth, Port Elizabeth, South Africa in 1987, and B CommHons (business management) University of Port Elizabeth, Port Elizabeth in 1989, and M Comm (business management) Vista University, Port Elizabeth, South Africa in 1995, He got a PhD (business management) Vista University, Port Elizabeth, South Africa in 1999.

He has 20 years lecturing experience and has published extensively in various journals and conference proceedings. He has published 30 articles in national and international journals and presented papers in 30 conference proceedings. He is currently a full professor at the Nelson Mandela Metropolitan University in Port Elizabeth, South Africa. His main research interests are strategic management, ethics and social responsibility, sustainability and organisational behavior.

Prof. Smith is a member of the Southern African Institute of Management Sciences and also serves on various committees at the Nelson Mandela Metropolitan University 